Dragan Đurđević

Srećko Manasijević

Momčilo Miljuš

https://doi.org/10.21278/TOF.43409

ISSN 1333-1124

eISSN 1849-1391

\title{
RATIONALIZATION OF A CORE WAREHOUSE IN THE CASTING PLANT: A CASE STUDY
}

\begin{abstract}
Summary
The warehouse is an important factor in the manufacturing process. At present, there are constant demands for the more efficient and effective operation of warehouse systems. For this reason, the rationalization of existing warehouses and/or storage systems is one of the ways to achieve the previously set targets. The possibilities of rationalization are numerous in all segments of the observed system. The most suitable solutions for a particular warehouse will be found based on the nature of the observed problem and the available investment funds. The paper defines the place and the role of the warehouse in a casting plant. Besides, the current situation in the warehouse segment of casting plants is analyzed to identify problems. Finally, the development of different concepts of rationalization to relevant constraints is discussed. This approach has enabled us to solve the problem of the rationalization task and to produce the desired effects.
\end{abstract}

Key words: $\quad$ Warehouse, rationalization, logistics processes, cores, casting

\section{Introduction}

The production process is associated with a set of new procedures, without which the primary production activity would be significantly compromised. To ensure the continuity of production in any manufacturing system, it is necessary to have a constant input of various materials, which means that it is required to have an appropriate warehouse as a part of global logistics support. Besides, the production process is a generator of materials handling $(\mathrm{MH})$ activities. In general, these activities include the flow of materials between spatially dispersed production departments, workplaces and/or storage areas that are interconnected in the production chain.

The primary task of rationalization of an industrial process is to achieve maximum efficiency, economy, and security of primary production; it requires, besides the rationalization in the field of production technology, the rationalization of all integrated processes, among which MH processes can be emphasized as the basic ones. Therefore, it seems logical to rationalize and define these processes in such a way that they would not endanger the production processes, thereby increasing costs and jeopardizing competitive ability. In this specific case, the current state in the logistics processes (materials handling processes in particular). In one segment of the casting, the plant indicates excellent potential for their rationalization. 
In the case of a casting plant, this problem is identified, but it is not sufficiently discussed in the available literature.

The studies [1-4] related to warehousing processes are primarily oriented to analysis and theory and do not provide a systematic method for warehouse rationalization. Exceptions are papers [5,6], which show two approaches to warehouse analysis and optimization. The focus of the paper [5] is on the order-picking process and its improvement in a warehouse of the Italian distribution company. A methodology, which enables an efficient order fulfillment system analysis, is provided. In the paper [6], the authors propose an integrated approach to the warehouse analysis and optimization using several tools borrowed from lean manufacturing. The use of such an approach was presented in a case study of the design of the warehouse.

Therefore, the purpose of this paper is to present the basic steps in the methodology of possible rationalization in the case of a core warehouse in one segment of the casting plant (here, only a logistics treatment of the cores is concerned). In this paper, the applied methodology of rationalization is based on two methods: system engineering and system approach. The basic steps in the methodology are:

- Definition of the place and role of a core warehouse in the casting plant,

- Analysis of the current situation (As-is process analysis),

- Identification of problems,

- Definition of various solutions,

- Evaluation of various solutions and selection of the most convenient one,

- Presentation of the solution.

The remainder of this paper is organized as follows: Section 2 is devoted to the problem statement, Section 3 is related to the methodology of rationalization steps, Section 4 describes a particular example - the development of the technological rationalization concept, and the final section gives conclusions with an overview and discussion of the results of the proposed rationalization solution.

\section{Problem statement}

Casting is a process in which the molten metal is poured into moulds in which it is cooled, and the castings get the desired shape. Cores of sand and binder are inserted into the mould to obtain cavities. Production of cores is an essential part of the manufacture of cast parts with holes. In addition to the core production department (CoPD), the technological process of casting involves other functional departments, e.g., melting, pouring, solidification, core removal, fettling and trimming, control, heat treatment, packaging and so on, which are interconnected. Based on the melting and casting production processes, the process of core production was defined [7].

The core warehouse $(\mathrm{CW})$ seems to be an essential part of the production process in a casting plant, with the primary task of providing a quantitative and timely balance between the two phases of the observed casting process: (i) the production of sand cores and (ii) the pouring and solidification processes (consumption of cores). Both processes are followed by several sets of materials handling processes, which are mainly governed by the regime and conditions imposed by the primary casting production. The production of cores at the casting plant is defined as follows: the produced cores must be dried for at least eight hours in the warehouse area before they are delivered and included in the production phase. Also, the firstin, first-out (FIFO) regime of core shipping needs to be adopted in all production chains in the casting plant. 
Based on the as-is analysis of the current state in the casting plant/core warehouse (onsite recording and information collected from the employees in the casting plant), the following problems.

- Storage of stocks in carts on the floor (at one level), which results in the lack of storage space and inadequate conditions for efficient materials handling processes in the core warehouse,

- due to the enormous weight of loaded (but also unloaded) carts and due to the condition of their wheels, manual labor is intensified during the transport,

- the search for the appropriate cores in-stock units, the application of FIFO regimes, the traceability of material flows are made considerably more difficult.

Based on the problems stated above, it is evident that there is an urgent need for the revision of the existing solution adopted in the core warehouse and of its rationalization. Therefore, the main task was to find a solution for the rationalization of the core warehouse and the materials handling process; the solution should minimize investments required for improving the efficiency of the existing core warehouse, mainly by using the available resources. The basic requirements for this task are as follows:

- To provide sufficient capacity of the core warehouse to ensure the smooth casting process,

- To provide the necessary equipment for the storage/retrieval and handling of materials to be able to monitor the planned dynamics of material flows,

- To ensure the application of the FIFO regime for the handling of cores, and

- To provide the traceability of material flows in the MH and production processes.

\section{Possible directions of rationalization}

In practice, there are numerous possibilities for the rationalization of warehouse systems. Generally, they can all be classified as technical and technological, as well as organizational and informational measures [8]. The choice of rationalization measures largely depends on the nature and types of the identified problems and their roots, on investment funds, and other constraints. Analyzing the identified problems from the aspect of their roots, we can classify them into three main areas:

- Materials handling unit (MHU),

- The technology of storing, and

- IT support.

These factors may cause certain problems, either each them individually or, more often, together with others. For example:

- The storage technology applied in a MHU - storage (in the existing MHU - carts for cores) only at one level on the floor results in the inadequate utilization of storage space and very often in the blocking and difficult access to individual MHUs; this results in the need for additional handling and significant time losses in the MH processes.

- The relatively heavyweight of full carts (the weight of the cart plus the net weight of a load of approximately $450 \mathrm{~kg}$ ) together with possible defects of the cartwheel(s) and the damaged floor make the manual handling in the casting plant very hard.

- The warehouse technology of storing, the organization of work, and the IT support make the application of the FIFO regime difficult and make the required level of traceability of material flows in the production and $\mathrm{MH}$ processes impossible. The observed casting plant does not have an appropriate information system that would allow better management of its resources (e.g., some form of enterprise resource 
planning - ERP) or a warehouse management system (WMS). Under existing conditions, the management of $\mathrm{MH}$ processes is paper-based (identifying paper IP). In its current form and the organization of work, it does not provide all the necessary information for process management.

To define the required rationalization task, it is necessary to determine the following basic parameters of the task:

- A. spatial characteristics of the casting plant,

- B. relevant requirements of the $\mathrm{MH}$ process in the casting plant,

- C. information/management requirements.

\subsection{Spatial characteristics of the casting plant (CP)}

The analysis of spatial characteristics of the CP is focused on the construction characteristics of the building and the spatial layout of particular technological units. As a result, the information related to the available space with its relevant characteristics was obtained. The layout and dimensions of individual departments are shown in Fig. 1 (all dimensions are in $\mathrm{m}$ ).

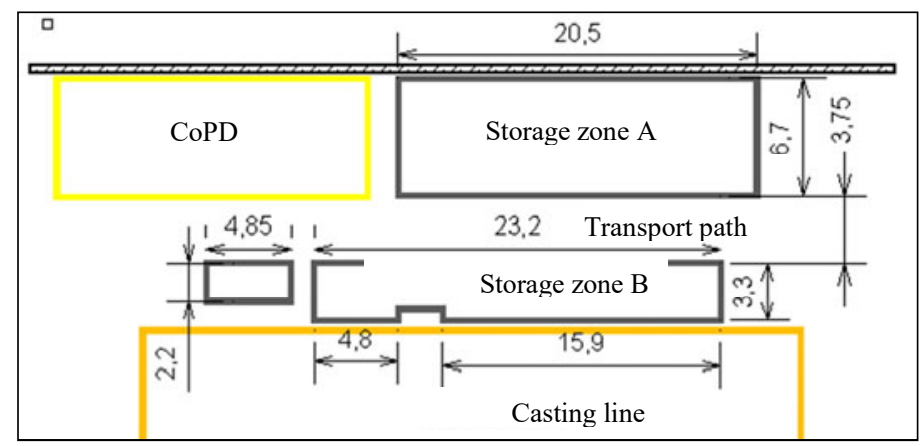

Fig. 1 Layout of technology departments in CP (dimensions are in $\mathrm{m}$ )

Two zones of 6 meters in height, A and B, are available as a potential space for storage.

3.2 Key requirements to be met by materials handling $(\mathrm{MH})$ processes in the casting plant (CP)

To define the key requirements to be met by the $\mathrm{MH}$ processes in the $\mathrm{CP}$, it is necessary to determine the relevant input. To fulfill this task, the following analysis was carried out:

- Analysis of the operating conditions and characteristics of the process of production and consumption of cores in the $\mathrm{CP}$,

- Determination of the relevant forms and quantities of cores,

- Determination of the parameters of relevant flows in the CP,

- Determination of the relevant requirements for information and management.

3.2.1 Analysis of operating conditions, process and production characteristics and consumption of cores in the $\mathrm{CP}$

The analysis of operating conditions includes the determination of time parameters of the operation of the $\mathrm{CP}$ with special emphasis on two processes - the production and the consumption of cores.

Core production: The production is carried out on five machines of the same type, which operate independently. Depending on the production plan (defined by the commercial department and the customer demand), the required batch size, and assortments, all five 
machines can simultaneously produce the same or different core(s). One machine can produce 18-22 cores per hour or 165-170 pieces per shift. Taking into account the number of expected scraps, the set-up time, and other technology-imposed times, one machine produces about 150 cores per shift in real conditions. In practice, one machine is utilized at about 0.85 , which results in the production of a total of about 2200-2250 good quality cores (pieces/24 h).

Core consumption: The casting process is carried out in two furnaces, which work in the "batch" or the "lot" mode; one batch of 2-tonne capacity requires the consumption of 100 cores. One lot provides enough liquid metal for the 30-45 minute production (time depends on the size of cast products). Under normal casting conditions, two casting furnaces require approximately $2400-2600$ cores per day.

\subsubsection{Determination of relevant forms and quantities of cores}

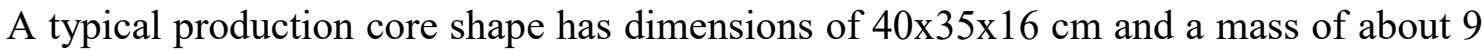
$\mathrm{kg}$. In the investigated $\mathrm{CP}$, carts with a capacity of 50 cores were used during production; those carts are also used as the basic MHU in the MH processes. This capacity is a result of matching the batch consumption in one cycle of the casting process of 100 cores, and e.it corresponds to the "consumption" of two carts.

Taking into consideration the mode of operation and the volume of production and consumption of cores, stocks of 5000 cores are defined; this stock corresponds to the two-day use. Expressed in carts, the actual level of core stock requires simultaneous storage of 100 carts, which is also the actual warehouse capacity.

\subsubsection{Determination of relevant parameters of flows in the $\mathrm{CP}$}

By observing the process of production and consumption of cores, three basic flows can be identified:

- Flow 1 - a movement of loaded carts from the CoPD to the storage area,

- Flow 2 - a movement of loaded carts from the storage area to the place of consumption - the casting line,

- Flow 3-a movement of empty carts or carts with the rest of the cores (the cores that have not been consumed on the casting line) to the CoPD.

Flow 1: Movement of loaded carts from the CoPD to the storage area. This flow depends on the production level/volume of the core -making machine. When all five machines simultaneously produce cores, the total production is about 750 cores per shift, which corresponds to the rate of flow 1 of 15 carts per shift, or about one cart per 30 minutes.

Flow 2: Movement of loaded carts from the storage area to the place of consumptionthe casting line. This flow defines the production of the casting line; according to the size of the batch of a single furnace, two carts (with 50 cores) are required for the casting interval of 30-45 minutes. In the usual operating mode, two casting furnaces consume 2400-2600 cores per day, which corresponds to a rate of about 50 carts per day (flow rate of flow 2).

Flow 3: Movement of empty carts or carts with the rest of the cores from the casting line to the CoPD. Under normal conditions, this flow is characterized by the flow of empty carts and the flow of carts for additional loading.

Flow 3 is realized in the following ways:

Flow 3a: Direct movement of empty carts from the place of consumption - from the casting line to the CoPD. This flow is realized when, at the moment of the unloading of the carts, any of the machines in the CoPD requires empty carts. The rate of flow $3 a$, according to the empirical data, ranges from 44 to 45 carts per day and is realized at a short distance.

Flow 3b: Movement of empty carts from the casting line_to the CoPD via the storage area. This flow is realized when, at the moment of core unloading from the carts to the 
casting line, the CoPD does not require empty carts; - thus, they are moved to the storage area (Flow 3b-1), from which they are shipped to the CoPD when it requires empty carts (Flow 3b2). The rate of flow $3 b$ is relatively low, i.e., about 5 to 6 carts per day.

Flow 3c: Direct movement of still partially loaded carts from the casting line to the CoPD for additional loading. This flow takes place when the delivered cart is not completely discharged on the casting line. If at the moment of the partial unloading of the cart, some of the core-making machines produces an article that is already on this cart, that is a precondition for direct movement (with or without short waiting time) from the casting line to the CoPD. The rate of flow $3 c$ is one cart per day.

\section{Flow 3d: Movement of carts from the casting line to the CoPD via the storage area.}

This flow is realized if, at the moment, when the carts are unloaded, no core machine produces articles placed on these carts. In such situations, these carts are moved to the storage area (flow 3d-1), and there, they wait for the start of the production of this article in the CoPD (flow $3 \mathrm{~d}-2$ ). The rate of flow $3 d$ is one cart per day.

\subsubsection{Determination of the relevant information and management requirements}

In the current mode of operation, the process management is carried out using a form in which the appropriate boxes are filled in at certain stages of the process. The information defines the type of the cores, the date and the shift of production, and the machine on which the cores have been made, the cart identification number, and some other relevant data. However, to handle the carts efficiently by the defined flows and specified requirements, the following additional information should be provided:

- the resources engaged in the MH process (storage location, handling equipment, operator), and

- management information requirements (management of $\mathrm{MH}$ processes - data on the operator's task, storage location, and retrieval of MHU, confirmation of the task completion, and adequate database updating).

Also, identification tags are required for storage locations, conveyor zones, and locations of operators - forklift drivers and materials handling equipment.

Based on the previous analysis and the achieved results, various technological concepts of rationalization have been developed, as shown below.

\section{Development of the technological concept of rationalization}

Technology and economy are the primary factors that influence the application of certain technological concepts in the warehouse [8]. In this context, the MH task is very important in the development/selection of different technological concepts, which include all relevant characteristics that the selected technology should achieve. Thus, for example, variable characteristics of the task (as in this case), such as complexity of the task and variability of product assortments in time, make the flexibility of the applied technology/solution very important.

Taking into account this important aspect along with other relevant characteristics of the described task (related to the available space, limitations, investment funds, etc.), technological concepts of rationalization, which can successfully fulfill such requirements, are being developed.

A technological concept (TC) is a set of typical technologies that include the fulfillment of all requirements in the analyzed system. The TC in a warehouse incorporates the structure and the relation between the technological requirement and the technological element in order to define it precisely. In addition to selecting typical technologies for a single technological 
concept to be introduced in a warehouse, it is necessary to add information related to the organization of work, the form of management, and the potential layout of the warehouse. As typical technologies in a warehouse must function as a unique system, it is also necessary to provide a way to manage the operation of certain technological elements. Also, during the development of the warehouse technological concept of all proposed typical technologies, the location requirements and constraints need to be satisfied. The adoption of typical technologies involves preliminary dimensioning of technological elements to verify the applicability in a given/available space and the quality of task completion.

4.1 Selection of system elements (resources) for the warehouse technological concept (WTC)

The process of developing and defining the warehouse technological concept requires the selection of basic components and/or elements of the system (resources), such as the type of MHU, materials handling equipment (MHE), storage equipment, and the integration of all these components into the available space in the warehouse. Various warehouse technological concepts are developed, taking into account the characteristics of problems and constraints. They are based on the application of the proposed MHU instead of the existing carts, forklifts as an $\mathrm{MH}$ solution, and selective racks as a storage solution. These three basic components of the warehouse technological concept are described in the text below.

\subsubsection{The proposed materials handling unit (MHU)}

By the primary production technology, the basic MHU is proposed as a "carrier" to be used instead of the existing cart; the "carrier" also has a capacity of 50 cores and a net mass of $450 \mathrm{~kg}$ in the MHU. Two basic MHU variants of carriers (N1 and N2) were considered; the basic parameters and shapes of both options are given in Table 1. The intended structure of the proposed MHUs should be such that the MH processes can be handled by the existing forklifts as well as by pallet trucks with manual operation.

Table 1 Basic parameters and shape of the proposed variants of MHUs for cores

\begin{tabular}{|c|c|c|c|c|c|}
\hline \multirow{2}{*}{$\begin{array}{l}\text { MHU } \\
\text { Type }\end{array}$} & \multirow{2}{*}{$\begin{array}{c}\text { Measures } \\
\text { Lenghtxwidthx } \\
\text { height }(\mathbf{m m})\end{array}$} & \multirow{2}{*}{$\begin{array}{c}\text { Number of } \\
\text { cores at one } \\
\text { level of MHU } \\
\text { (pcs) }\end{array}$} & \multirow{2}{*}{$\begin{array}{c}\text { Number of } \\
\text { levels for } \\
\text { cores in } \\
\text { MHU }\end{array}$} & \multicolumn{2}{|c|}{ Shape of MHU } \\
\hline & & & & N1 & $\mathbf{N 2}$ \\
\hline $\mathrm{N} 1$ & $1400 \times 820 \times 1960$ & 6 & 9 & & \\
\hline $\mathrm{N} 2$ & $1400 \times 1250 \times 1330$ & 9 & 6 & & \\
\hline
\end{tabular}

\subsubsection{The proposed materials handling equipment}

For the handling of MHUs, the use of forklifts with appropriate technological characteristics is proposed. In the considered casting plant, certain types of forklifts are already used, some of which are used both in the core product and the core warehouse departments and in other technological departments of the casting plant. Therefore, to minimize the investment costs for the development of various warehouse technological concepts, the following forklifts were considered: counterbalanced forklift truck and electric pedestrian stacker.

In the process of defining specific characteristics of various warehouse technological concepts, the materials handling equipment units have a restraining influence on other technological elements and/or the layout of the storage area in terms of a sufficient aisle width (Ast), maximum lifting height and loading capacity. In accordance with recommendations given in [9], as well as with the relevant characteristics of the MHUs and forklifts, three basic parameters relevant to forklifts are given in Table 2. 
Table 2 Parameters relevant to forklifts

\begin{tabular}{lcccc}
\hline \multirow{2}{*}{ Parameters } & $\begin{array}{c}\text { Counterbalanced } \\
\text { forklift }\end{array}$ & \multicolumn{2}{c}{$\begin{array}{c}\text { Electric } \\
\text { pedestrian } \\
\text { stacker }\end{array}$} \\
\cline { 2 - 5 } & N1 & N2 & N1 & N2 \\
\hline Min. aisle width, (m) & 4.5 & 4.5 & 2.7 & 2.8 \\
Lifting height, (m) & 3.15 & 3.15 & 2.8 & 2.8 \\
Loading capacity, (kg) & 2500 & 2500 & 1600 & 1600 \\
\hline
\end{tabular}

\subsubsection{The proposed storage technology}

Selective racks proposed as a storage technology result in the FIFO regime and easy access to the cores in the observed casting process. The choice of a particular rack design (size of rack cells - the storage capacity and the number of rack levels) is made according to the constraints imposed by the materials handling units and equipment, and the characteristics of the available space in the core warehouse.

Racks with two cells in height are used here; the reason for this solution is the maximum lifting height of both proposed forklift types. Also, rack cells for the storage of two MHUs are proposed (Fig. 2). Rack cells with three MHUs are not considered since their use increases the cost of necessary construction work and makes the use of available space difficult, which is in contrast with the basic principles of the development of various warehouse technological concepts.
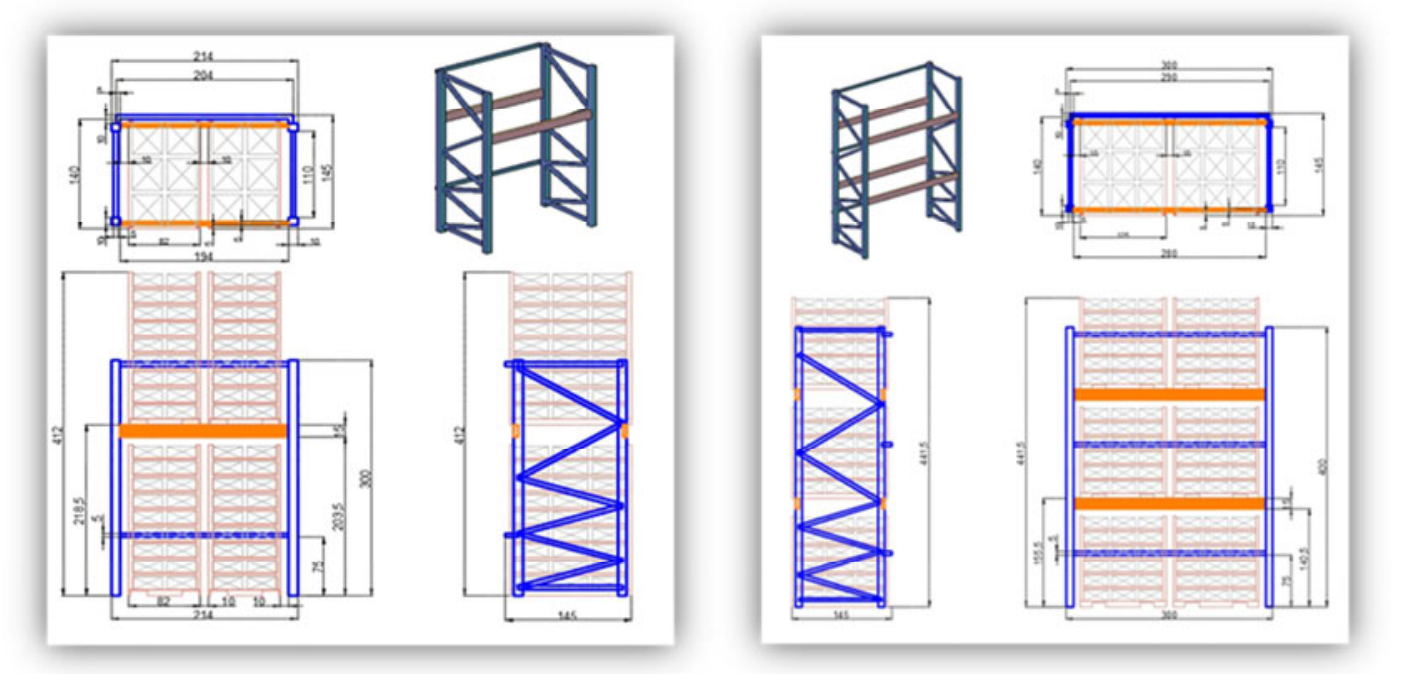

Fig. 2 The shape of the rack with two MHUs in the rack cells (N1 and N2 variants of MHUs)

\subsection{Dimensioning of materials handling system elements}

The required number of forklifts is calculated based on the cycle time, which consists of a series of partial activities. The total cycle time of the forklift in the flow $F(F 1,2$, and 3 described in paragraph 3.2.3.) is equal to the sum of the duration of all activities; it may be expressed as:

$$
T_{c}^{F}=\rho \sum_{i=1}^{N_{F}} t_{i}
$$

where

$t_{i} \quad$ - time of activity $i$ in the flow $F$,

$N_{F}$ - total number of activities in the cycle of flow $F$,

$\rho \quad$ - time reduction coefficient (some activities in the cycle are carried out simultaneously). 
The duration of an activity in the cycle $\left(t_{i}\right)$ can be obtained in two ways: (i) by evaluations based on previous experience or statistical analysis of the sample obtained by recording a particular activity, and (ii) by calculation based on the real conditions under which the activity is carried out.

In the calculation done in the real conditions, the experiential time values of the cycle activities that are not dependent on various warehouse technological concepts were used for the identified flows (Table 3).

Table 3 Time values estimated based on experience in the identified flows

\begin{tabular}{lc}
\hline \multicolumn{1}{c}{ Activity } & $\begin{array}{c}\text { Estimated } \\
\text { time, (s) }\end{array}$ \\
\hline Picking of MHU from a rack cell or the floor & 10 \\
Putting MHU in a rack cell or on the floor & 10 \\
Turning of MHE in the direction to the desired destination & 5 \\
Waiting time of forklift driver by machine in CoPD & 10 \\
Waiting time of forklift driver to department foreman & 30 \\
Waiting time of forklift driver on the casting line & 30 \\
Waiting time of forklift driver in the storage area & 5 \\
$\rho$ - time reduction coefficient & 0.9 \\
\hline
\end{tabular}

The values of the activities to be calculated are a function of the characteristics of various warehouse technological concepts and the components related to the movement distances and the lifting/lowering height as well as the speed of materials handling equipment at these distances/heights. The movements and lifting/lowering speeds of the proposed forklifts are shown in Table 4. The movement times are calculated using the equation $t_{i}=\frac{L_{a}}{V_{v}^{T C}}$, where $L_{a}$ is the movement distance of the forklift during the activity $a$, while $V_{v}^{T C}$ is the speed of the forklift on $L_{a}$ for $T C$.

As for the speed calculation, $75 \%$ of the maximum speed of the forklift from Table 4 was used during the cycle time in the horizontal movement. The movement distances at the horizontal level depend on the layout of technological elements in that particular warehouse technological concept. Also, the relevant horizontal distance of each flow was applied as the maximum two-thirds of the actual distance [10,11].

The load lifting/lowering height is also dependent on the warehouse technological concepts, in our case, on the-proposed selective racks. The expected lifting and lowering heights of the MHUs are $1.105 \mathrm{~m}$ and $0.79 \mathrm{~m}$ for $\mathrm{N} 1$ and $\mathrm{N} 2$, respectively.

Table 4 Maximum speeds of forklifts

\begin{tabular}{l|c|c|c|c}
\hline \multirow{2}{*}{ Activity } & \multicolumn{2}{c}{$\begin{array}{c}\text { Counterbalanced } \\
\text { forklift }\end{array}$} & \multicolumn{2}{c}{$\begin{array}{c}\text { Electric pedestrian } \\
\text { stacker }\end{array}$} \\
\cline { 2 - 5 } & With load & $\begin{array}{c}\text { Without } \\
\text { load }\end{array}$ & With load & $\begin{array}{c}\text { Without } \\
\text { load }\end{array}$ \\
\hline Travel speed at the horizontal level, $(\mathrm{m} / \mathrm{s})$ & 6.11 & 6.11 & 1.66 & 1.66 \\
Lifting speed of MHU, $(\mathrm{m} / \mathrm{s})$ & 0.55 & 0.56 & 0.14 & 0.22 \\
Lowering speed of MHU, $(\mathrm{m} / \mathrm{s})$ & 0.56 & 0.56 & 0.4 & 0.35 \\
\hline
\end{tabular}

The total engagement of forklifts during the day in a technological concept $\left(T^{T C}\right)$ is obtained by multiplying the time $\left(T_{C}^{i}\right)$ and the expected number of forklift cycles $\left(N R_{i}\right)$ in the flow $i$ (Equation 2):

$$
T^{T C}=\sum_{i=1}^{N_{F}} T_{C}^{i} N R_{i}
$$

The expected number of forklift tasks per day is obtained by several analyses done by the authors of this paper and an assessment of the experienced staff of the casting plant (Table 5). 
Table 5 Estimated forklift tasks per flows (number per day)

\begin{tabular}{lc}
\hline \multicolumn{1}{c}{ Flow - activity } & $\begin{array}{c}\text { Estimated } \\
\text { NR }\end{array}$ \\
\hline $1-\quad$ Storage of loaded MHU (carrier) from the CoPD to the storage area & 45 \\
$2-\quad$ Movement of loaded MHU from the storage area to the casting line & 50 \\
$3 a-$ Movement of empty MHU from the casting line to the CoPD & 45 \\
3b-1 - Movement of empty MHU from the casting line to the storage area & 5 \\
3b-2 - Movement of empty MHU from the storage area to the CoPD & 5 \\
3c - Direct movement of MHU for additional loading from the casting line to the CoPD & 1 \\
3d-1 - Movement of MHU for additional loading from the casting line to the storage area & 1 \\
3d-2 - Movement of MHU for additional loading from the storage area to the CoPD & 1 \\
\hline
\end{tabular}

The presented methodology is based on the assumption that each cycle is carried out independently, i.e., without using the double cycle realization. This approach ensures a significant additional capacity for forklift engagement as this calculation approach enables the control of the capacity of materials handling equipment in the case of extremely challenging tasks. It is also used here for the estimation of the sufficiency of the available mechanization. In general, if a more precise calculation of assets of engagement is needed, it is possible to apply simulation and one of the analytical models [12].

4.3 The layout of elements of a technological concept in a warehouse

The development of various warehouse technological concepts in this step implies the layout of its elements. For the previously described MHUs, and therefore the two types of selective racks, as well as the two types of forklifts, different warehouse technological concepts were examined.

The principles applied in the development of various warehouse technological concepts are:

- achieving the storage capacity of a minimum of 100 MHUs,

- rack arrangement that ensures the minimum space required for handling forklifts with $\mathrm{N} 1 / \mathrm{N} 2$,

- possible future expansion of CoPD (primarily in Zone A), and

- spatial requirements for maintaining the casting line (in Zone B).

In the process of layout development, warehouse technological concepts based on the application of the N2 MHU did not fulfill the requirement of the required storage capacity of 100 carriers, and they were excluded from further consideration. Two available warehouse technological concepts (WTC) are shown in Fig. $3 a$ and $3 b$.

WT 1 and WTC 2 are based on the application of the N1 MHU, the appropriate racks for storage, and an electric pedestrian stacker or counterbalanced forklifts as the appropriate materials handling equipment.

a)
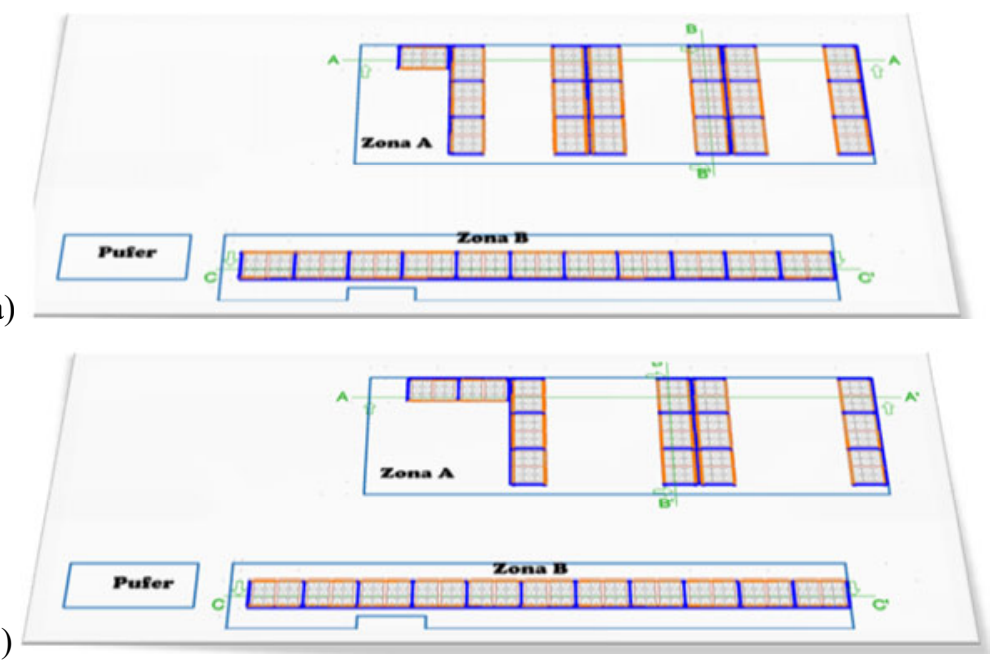

b)

Fig. 3 Rack layout: a) WTC 1 and b) WTC 2 


\subsection{Evaluation of two warehouse technological concepts and proposal of the solution}

Relevant parameters of the two warehouse technological concepts are given in Table 6. According to the capacity of the storage area, WTC 1 has an advantage over WTC 2. However, the consideration of flexibility criteria leads to a different conclusion. Namely, WTC 2 enables the simultaneous engagement of both existing forklifts in the carrying-out of the $\mathrm{MH}$ processes. This largely eliminates the possibility of downtime in the functioning of the system in case of failure of the electric pedestrian stacker.

In both WTC 1 and WTC 2, the engagement of only one forklift is sufficient for the completion of all $\mathrm{MH}$ activities in the observed flows, but a counterbalanced forklift truck is engaged for a shorter time, which leaves more possibilities for its engagement in other processes within the casting plant.

Regarding the flexibility of the occupied space, WTC 1 has an advantage over WTC 2; - removal of the rack closest to the CoPD does not reduce the capacity of the storage zone below the required level, and it enables an increase in the number of machines in the CoPD. This is not the case with WTC 2, whose storage capacity is thus reduced to 92 MHUs. The above-described criteria should be analyzed before deciding between WTC 1 and 2; the decision depends on the future CoPD plans and constraints.

Table 6 Presentation of parameters of the two WTCs

\begin{tabular}{cccccccccc}
\hline WTC & MHU & $\begin{array}{c}\text { Forklift } \\
\text { type }\end{array}$ & Rack & \multicolumn{3}{c}{ Capacity } & \multirow{2}{*}{$\begin{array}{c}\text { Applied } \\
\text { MHE }\end{array}$} & $\begin{array}{c}\text { Time } \\
\text { consumption } \\
\text { of MHE/day }\end{array}$ \\
\cline { 5 - 6 } 1 & $\mathrm{~N} 1$ & $\begin{array}{c}\text { Electric } \\
\text { pedestrian } \\
\text { stacker }\end{array}$ & 2 & 76 & 44 & 120 & $\begin{array}{c}\text { Electric } \\
\text { pedestrian } \\
\text { stacker }\end{array}$ & $4.08 \mathrm{~h}$ \\
$2^{1)}$ & $\mathrm{N} 1$ & $\begin{array}{c}\text { Counterbala } \\
\text { nced forklift }\end{array}$ & 2 & 56 & 48 & 100 & $\begin{array}{c}\text { Zone B } \\
\text { Counterbalanc } \\
\text { ed forklift }\end{array}$ & Total & $2.91 \mathrm{~h}$ \\
\hline
\end{tabular}

${ }^{1)}$ Electric pedestrian stacker could also be applied

\subsection{The concept of the information management system (IMS)}

The proposed IMS was developed to enable an efficient MH process that contributes to the fully-functioning production in the casting plant. Also, the requirements for the FIFO regime of the stock of cores and traceability of material flows in the $\mathrm{MH}$ processes and production are satisfied. Furthermore, the proposed IMS does not require additional investment - the existing IMS based on the accompanying form (AF) has been modified to include the missing information that would allow traceability and the usage of the FIFO regime in the management of production and the use of cores. The proposed AF (Fig. 4) assumes that all personnel involved in the $\mathrm{MH}$ processes should confirm the realization of their activities by filling out and signing the appropriate boxes in the form. The accompanying forms will be printed in two lists to enable adequate process management. Also, adequate filling-in of the AFs allows for the application of the FIFO regime. The testing of several typical tasks proves the efficiency of the proposed solution.

Accordingly, the proposed concept of IMS requires/includes the following: MHU coding, marking of storage locations, and identification of all operators and participants (e.g., materials handling equipment, driver, managers, etc.) in the flows. 


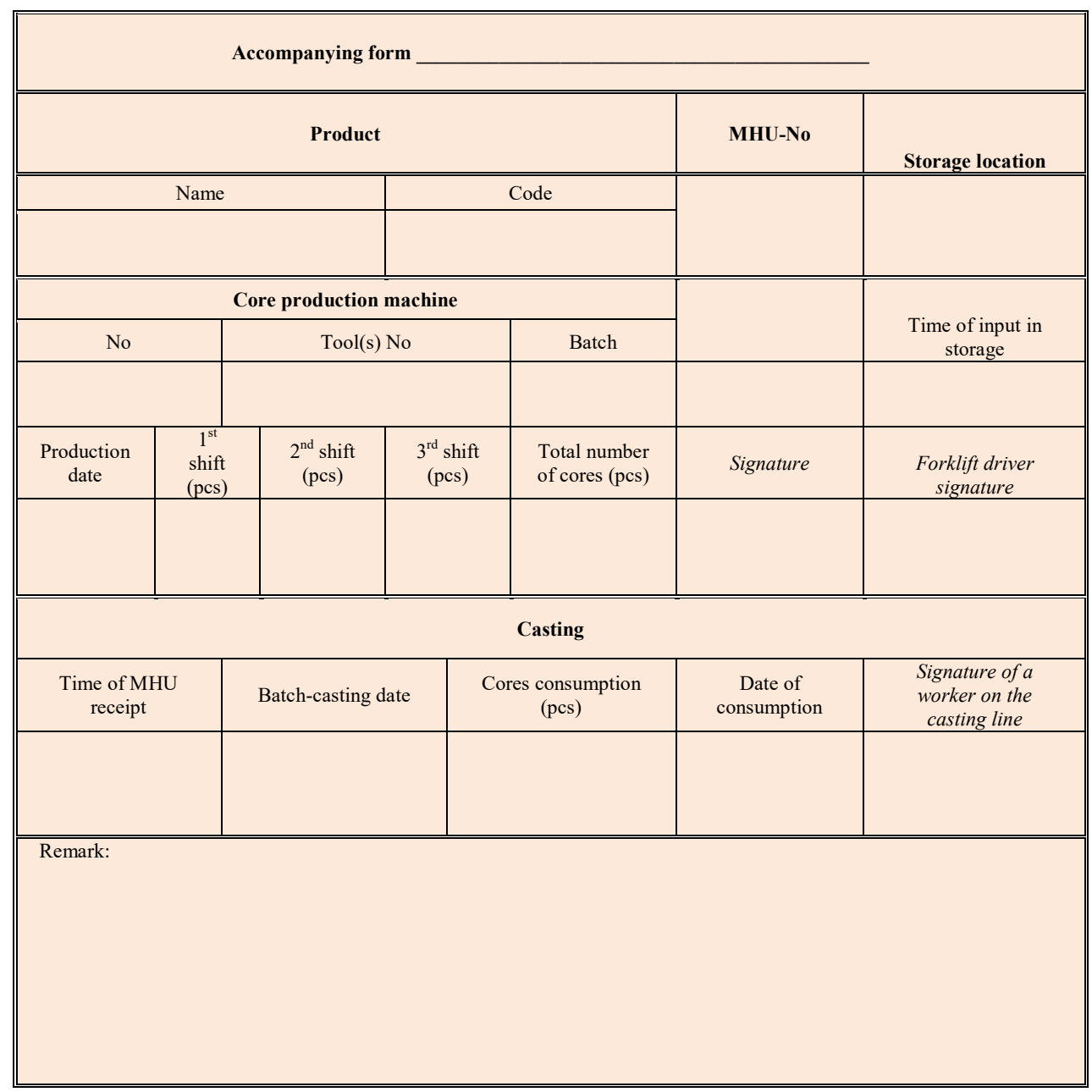

Fig. 4 The accompanying proposed form (AF)

\section{Conclusion}

This paper presents one of the possible directions in the rationalization of the core warehouse in the real casting plant. The task of rationalization was to find a technological solution that would enable the use of the existing available resources and would require a minimum investment, but that would also enable the functioning of the casting plant with the desired effects. The proposed solution meets all the basic requirements from the set of defined rationalization tasks: (i) the proper way of storage of the required capacity (stock of 5000 cores) is achieved by introducing the proposed rack, and material handling unit, (ii) intense manual labor is avoided by introducing the proper shape of materials handling unit and by using available forklifts, (iii) the tracking and tracing of appropriate core stock units, the application of FIFO regimes, the traceability of material flows are ensured.

It should be concluded that different technologies can improve the analyzed process. Thus, more complex techniques used for satisfying the MH requirements (automation, automated guided vehicles, robots, etc.) require sophisticated information and communication technologies (e.g., enterprise resource planning - ERP and warehouse management system WMS). This requires significant investment and generates additional tasks in the field of necessary project management. Such task(s) could be of interest to new research in this field.

In this paper, the applied methodology is presented using one example for a type of rationalization task in a particular case study; this is an important limitation of this study. 
Future work could be extended to a broader range of situations (other types of rationalization tasks). In that case, potential solutions should include a wider spectrum of potential technologies (e.g., automatization and application of robots) as well as a higher level of information and communication technologies. Further research within the proposed methodology might be to define tasks of rationalization and the process of generating potential technologies in accordance with the task.

\section{REFERENCES}

[1] Rouwenhorst, B.; Reuterb, B.; Stockrahmb, V.; Van Houtumc, G.J.; Mantela, R.J.; Zijmc, W.H.M. Warehouse Design, and Control: a framework and a literature review, European Journal of Operational Research 2000, 122, 515-533. https://doi.org/10.1016/s0377-2217(99)00020-x

[2] Gu, J.X.; Goetschalckx, M.; McGinnis, L.F. Research on warehouse operation: A comprehensive review, European Journal of Operational Research 2010, 203(3), 539-549. https://doi.org/10.1016/j.ejor.2009.07.031

[3] Baker, P; Canessa, M. Warehouse design: a structured approach, European Journal of Operational Research 2009, 193(2), 425-436. https://doi.org/10.1016/j.ejor.2007.11.045

[4] Van Dyk, L. The philosophy - tool continuum, South African Journal of Industrial Engineering 2001, 12(1), 1-14.

[5] Regattieri, A.; Manzini, R.; Gamberi, M. The Logistics Reengineering Process in a Warehouse/Order Fulfillment System: A Case Study in Warehousing in the Global Supply Chain, Editor: Ricardo Manzini, Springer-Verlag London Limited, 2012, pp. 425-455. https://doi.org/10.1007/978-1-4471-2274-6_16

[6] Dotoli, M.; Epicoco, N.; Falagario, M.; Costantino, N.; Turchiano, B. An integrated approach for warehouse analysis and optimization: A case study, Computers in Industry 2015, 70, 56-69. https://doi.org/10.1016/j.compind.2014.12.004

[7] Zrnić, Đ.; Prokić, M.; Milović, P. Design foundry, Faculty of Mechanical Engineering, University of Belgrade, 1988.

[8] Vukićević, S. Warehouses, Preving, Belgrade. 1995.

[9] VDI-Standard. VDI 2199, The Association of German Engineers (VDI). 2012.

[10] Sretenović, M. Transhipment mechanization-transhipment machines, and design reloading processes, University book, University of Belgrade, 1996.

[11] Vidović, B.M. Quantitative analysis of the material handling system, Faculty of Transport and Traffic Engineering, University of Belgrade, 2007.

[12] Djukić, G.; Opetuk, T.; Cajner, H.; Jakovljević, M.; Simulation Analysis of Models for Estimation of Empty Travel Time of Vehicles in Non-automated Material Handling Systems, FME Transactions 2018, 46, 336-341. https://doi.org/10.5937/fmet1803336d

Submitted: $\quad 22.8 .2018$

Accepted: $\quad 26.4 .2019$
Assist. Prof. Dragan Đurđević, PhD d.djurdjevic@sf.bg.ac.rs

University of Belgrade, Faculty of

Transport and Traffic Engineering, Vojvode Stepe 305, 11000 Belgrade, Serbia

Srećko Manasijević *, PhD srecko.manasijevic@li.rs

Lola Institute Ltd., Kneza Višeslava 70a, 11 030, Belgrade, Serbia

Full Prof. Momčilo Miljuš, Ph.D mmiljus@sf.bg.ac.rs

University of Belgrade, Faculty of

Transport and Traffic Engineering, Vojvode Stepe 305, 11000 Belgrade,

Serbia

*Corresponding author, srecko.manasijevic@li.rs 